\title{
OS HERDEIROS E OS BOLSISTAS DO PROUNI NA CIDADE DE SÃO PAULO
}

\author{
Wilson Mesquita de Almeida*
}

RESUMO: $\mathrm{O}$ artigo discute dados de uma pesquisa empírica efetuada com 50 bolsistas do Programa Universidade para Todos (ProUni) na cidade de Sáo Paulo, dialogando com reflexôes presentes em Os Herdeiros. Utilizou-se a metodologia qualitativa na análise das entrevistas e dos questionários por meio da articulação das condiçóes familiares e de trabalho e das experiências de acesso e permanência dos bolsistas no ensino superior privado lucrativo. Os resultados sugerem diferenças importantes entre três subgrupos de bolsistas (bacharelandos, licenciandos e tecnólogos), com acentuada positividade para os bacharelandos quando se compara com os outros dois subgrupos no que se refere à formaçáo escolar, origem social e econômica, condiçóes culturais e acesso a cursos e universidades mais prestigiados.

Palavras-chave: Ensino Superior Privado; Programa Universidade para Todos; Os Herdeiros; Desigualdades Educacionais.

\section{THE INHERITORS AND PROUNI'S SCHOLARS IN THE CITY OF SÃo PAULO}

\begin{abstract}
The article discusses data from an empirical research carried out with fifty higher education students enrolled in private institutions who were awarded scholarships from the University for All Program (ProUni) in São Paulo, by establishing a dialogue with reflections present in The Inheritors. Qualitative methodology was used in the analysis of interviews and questionnaires through the articulation of family and working conditions and access and permanence experiences in the forprofit higher education sector in Brazil. The results suggest important differences among three subgroups of scholars (who are either pursuing a bachelor's degree, a teaching licensure or a technologist degree), with marked positiveaspects for scholars pursuingabachelor's degreewith regard to their educational background, social and economic origin, cultural conditions as well as access to more prestigious courses and universities.
\end{abstract}

Keywords: Private higher education; ProUni - University for All Program; The Inheritors; Educational inequalities.

\footnotetext{
* Universidade Federal do ABC, Centro de Engenharia, Modelagem e Ciências Sociais Aplicadas, Políticas Públicas, São Bernardo do Campo, SP., Brasil. E-mail: wilson.mesquita@ufabc.edu.br
} 


\section{Les Héritiers et les boursiers ProUni À la Ville de SÃo Paulo}

RÉSUMÉ: L'article discute des données obtenues à partir d'une recherche empirique réalisée avec 50 boursiers du Programme Université Pour Tous (ProUni) à São Paulo, en parlant avec des réflexions présentes dans Les Héritiers. Nous avons utilisé une méthodologie qualitative dans l'analyse des entretiens et des questionnaires par l'articulation des conditions familiales et de travail et les expériences d'accès et de la permanence des boursiers dans l'éducation privée lucrative supérieure. Les résultats suggèrent des différences assez importantes entre les trois sous-groupes de boursiers (au Brésil il y a trois types d'étudiants: bacharelando, licenciandos et techniciens), avec une forte positivité pour les "bacharelando" par rapport aux deux autres sous-groupes à l'égard de la formation scolaire, de la provenance sociale et économique, les conditions culturelles et l'accès à des cours et des universités les plus prestigieuses.

Mots-clés: Enseignement supérieur privé; ProUni - Programme Université Pour Tous; Les Héritiers; Inégalités scolaires.

\section{A problemática da democratização do ensino superior: breves considerações e a relevância de Os Herdeiros}

U ma análise dos trabalhos a respeito da temática "democratização do ensino superior" revela que esta categoria pode ser sociologicamente apreendida sob um duplo aspecto: quantitativo e qualitativo. Uma democratização quantitativa aponta para um crescimento da taxa de escolarização entre as camadas sociais. Aqui democratizar significa difundir a instrução. (MERLE, 2000, p. 16; ERLICH, 1998, p. 57-58; LANGOUËT, 2002, p. 122) No entanto, o alongamento dos estudos entre os indivíduos de uma determinada sociedade, embora necessário, não é suficiente para que se tenha uma maior democratização do conhecimento escolar. Quando orientada para a diminuição das desigualdades dos percursos escolares ligadas à origem social, teríamos uma democratização qualitativa. É neste aspecto que se encontra a problemática maior dos estudos sobre democratização do ensino. O que está em causa é discutir como perseguir uma efetiva igualdade das oportunidades educacionais entre as diferentes frações de classes sociais. Em outros termos, como impedir ou atenuar que "barreiras extra-educacionais" acabem transformando direitos em privilégios sociais. (FERNANDES, 1966, p. 123-124)

Aqui reside uma das principais contribuições de duas obras conjuntas de Pierre Bourdieu e Jean Claude Passeron, Os Herdeiros (1964) e A Reprodução 
(1970). Durante a expansão escolar dos anos 1960, eles destacaram, por meio de pesquisas empíricas e inovaçóes conceituais, que os conceitos de capital cultural e reprodução social são exemplos, como as engrenagens operadas no espaço social escolar acabam por reproduzir, em um novo contexto social, oportunidades diferenciadas de acordo com a origem social do estudante. Foram os que mais aprofundaram o estudo sobre as estratégias mobilizadas pelas fraçóes de classes dominantes para manter ou reconverter o valor dos diplomas, face à entrada de segmentos que até então não circulavam nos ambientes universitários, relegando-os aos ramos e carreiras de menor prestígio, geralmente envoltas em processos de desclassificação simbólica. Por isso, suas reflexóes em Os Herdeiros ainda permanecem relevantes. Isso pode ser constatado em alguns estudos posteriores e nos mais recentes da sociologia educacional francesa que mantêm uma interlocução produtiva com os insights desenvolvidos pelos dois sociólogos franceses. Podemos remeter a Garcia e Poupeau (2003) que, ao estudarem os vieses dos indicadores estatísticos no debate sobre a democratização, utilizam termos como a "ocultação das hierarquias" entre os tipos de ensino que os indivíduos têm acesso e o esquecimento das "condiçôes sociais da certificação". Beaud e Pialoux (2001) e Beaud (2006; 2008), privilegiando uma perspectiva de tipo etnográfico para compreender os resultados da política de abertura do acesso escolar às crianças francesas dos segmentos populares, retomam teses antevistas por Bourdieu e Passeron em Os Herdeiros, demarcando a persistente remodelação das hierarquias do ensino superior francês contemporâneo frente às camadas socialmente mais destituídas que a ele têm acesso. Mesmo aqueles que têm como foco de pesquisa os "novos estudantes" franceses, socialmente diferentes dos "estudantes herdeiros", como Erlich (1998), utilizam-se de categorias como "restrição das escolhas" para compreender os processos de hierarquização social que marcam os diferentes cursos do ensino superior.

\section{Democratização à brasileira e a nova classe trabalhadora}

Quando analisamos o percurso histórico de acesso à educação superior brasileira - ainda hoje bem restrito se consideramos a população na faixa de 18 a 24 anos - é a partir dos anos de 1970 que se verifica uma expansão mais acentuada das vagas, com o acesso predominante de indivíduos das camadas médias. (CUNHA, 1975; RIBEIRO; KLEIN, 1982; ROMANELLI, 2001) Naquela época, a maior parte da demanda por ensino universitário foi absorvida pelo setor privado de ensino superior com fins lucrativos, incentivado durante o regime militar mediante isençóes fiscais e pelo financiamento estatal direto com a figura do crédito educativo, criado em 1976 e hoje denominado Fies (Fundo de Financiamento Estudantil). Os ditos "excedentes" - candidatos que atingiam a nota necessária para aprovação no vestibular, mas não suficiente para obter uma 
vaga - configuram a expressão daquele contexto histórico. As universidades públicas e as privadas confessionais, a partir da década de 1970, perderam a hegemonia no que diz respeito às vagas em nível de graduação para o até entâo setor mercantil nascente. ${ }^{1}$

Durante o governo Fernando Henrique Cardoso (1995-2002), ocorrerá uma segunda onda de expansão mais acentuada do ensino superior, também realizada no setor privado de cunho lucrativo. Dados do Ministério da Educação (MEC), sobre a evolução das matrículas, apontam que em 1995 as vagas do setor público correspondiam a 39,8\% do total e caíram para 30,2\% em 2001. Já as vagas no setor privado que correspondiam a $60,2 \%$ em 1995 , aumentaram para $69,8 \%$ em 2001. Em termos de luta pelo acesso, na segunda metade dos anos 1990, como resultado da ampliação da educação básica ocorrida no período, houve uma nova demanda de vagas reivindicadas por setores da classe média baixa e de baixa renda. (FILHO, OLIVEIRA; CAMARGO, 1999; DAUSTER, 2003; MOEHLECKE, 2004, p. 42; ALMEIDA, 2009)

Já nos anos 2000, mudanças ocorreram nas políticas de acesso ao ensino superior voltadas para os segmentos socialmente mais desprovidos. Nas universidades públicas, políticas de cotas e sistema de pontuação (bônus). No setor privado, a partir de 2005 surge o Programa Universidade para Todos (ProUni), um sistema de bolsas para os alunos mais pobres. A grande mutação foi o uso do Exame Nacional do Ensino Médio, o Enem, como método seletivo para o ensino superior em ambos os setores, seja para as vagas do ProUni (em 2004), seja, por meio do Sisu, o Sistema de Seleção Unificada ${ }^{2}$, para as vagas das universidades federais (em 2010). O fato a destacar é que a ampliação do ensino superior brasileiro ocorrida nos últimos anos teve e tem como via prioritária a educação privada lucrativa ${ }^{3}$ - uma resultante do caminho peculiar frente a outros países ao redor do mundo que os vários governos, desde o regime militar, elegeram para ampliar o acesso à universidade. Conforme apontam pesquisas sobre o perfil do alunado desse setor privado lucrativo, a maioria dos estudantes possui forte vínculo com o trabalho, notadamente para sustento pessoal, sustento de outros entes familiares ou mesmo para auxílio no orçamento doméstico. Logo, no Brasil, mais do que o estudante que trabalha, predomina o trabalhador que estuda. (SPOSITO; ANDRADE, 1986; HIRANO et al., 1987; SAMPAIO; LIMONGI; TORRES, 2000; TARTUCE, 2007; COMIN; BARBOSA, 2011)

Entre os anos 2003-2011, durante o governo de Luiz Inácio Lula da Silva, ocorreu um processo de redução da desigualdade de renda entre os grupos sociais brasileiros, levando mais de 30 milhóes de pessoas a ultrapassaram a linha de pobreza equivalente a um quarto do salário mínimo. Esse novo e expressivo contingente foi classificado como uma nova "classe econômica" - a nova classe $\mathrm{C}$ - que emerge na primeira década dos anos 2000. Como a renda dessa camada social passa a ser maior que a soma da renda de integrantes das classes A e B, 
houve e há uma euforia no ar, dada a massa financeira posta em circulação. Por isso, multiplicam-se notícias sobre a ascensão daquilo que as mídias e alguns autores designam como a "nova classe média brasileira". (NERI, 2011; SOUZA; LAMOUNIER, 2010) É importante precisar que, embora, incontestavelmente tenha ocorrido uma elevação na renda das camadas socialmente mais vulneráveis no Brasil contemporâneo, conforme apontam algumas pesquisas empíricas sobre esse novo segmento social, parte substantiva possui baixa escolaridade, atua na informalidade, possui moradias inadequadas, acesso limitado ao crédito, dentre outros marcadores sociais bem distantes das camadas médias, sendo esses indivíduos mais bem qualificados como constituintes de uma "nova classe trabalhadora". (SOUZA, 2010; POCHMANN; 2012; 2014; KERSTENETZKY; UCHOA, 2013) Um dos principais anseios dessa nova camada social é a busca da elevação de nível social a partir da obtenção do diploma do ensino superior. Os indivíduos da emergente classe C são o desejo maior dos grupos educacionais com açóes na Bolsa de Valores de São Paulo. Marcados por restriçóes de cunho financeiro e competitivo na disputa pelas vagas no ensino superior público, oriundos de uma escola pública cada vez mais desvalorizada e desfigurada, resta-lhes a busca pelo ensino superior privado lucrativo. O próximo tópico discute um subconjunto dessa nova camada social, os bolsistas do ProUni, procurando relacioná-los com aspectos e reflexôes discutidos, de forma pioneira, em Os Herdeiros.

\section{Os Herdeiros e os bolsistas do ProUni: lições a extrair}

A pesquisa foi efetuada com 50 bolsistas do ProUni, na cidade de São Paulo, oriundos de seis universidades privadas, sendo duas instituições confessionais. Foram realizadas 16 entrevistas e preenchidos 34 questionários com estudantes dos cursos de Direito, Engenharia Civil, Medicina, Educação Física, Enfermagem, Administração Geral, Economia, Psicologia, Publicidade, História, Tecnologia em Criação e Produção Gráfica, Letras, Pedagogia e Tecnologia em RH. A pesquisa empírica qualitativa foi estruturada em quatro eixos temáticos: família, trabalho, acesso à universidade e vida universitária. Essas quatro temáticas e seus tópicos constitutivos formaram um conjunto de evidências empíricas que procurou compreender as trajetórias estudantis de um grupo particular de universitários na cidade de São Paulo. Realizou-se uma sistematização de estudos de casos, comparando-os entre si e chegando a subconjuntos quando aspectos comuns os ligavam (pontos de aproximação, similaridades) e, também, privilegiando um olhar mais circunscrito ao trajeto individual, singular (aspectos diferenciadores, próprios), quando não nos foi possível classificá-los em grupos mais amplos. Assim, é imperioso lembrar que a "representatividade" ou "generalização" do estudo de caso está fundada no propósito heurístico de representar casos possíveis 
de ocorrer em contextos que apresentem características ou propriedades similares ou próximas àquelas por mim investigadas.

Quais os pontos de diálogo entre as evidências empíricas analisadas e a obra clássica Os Herdeiros, que completa meio século? Bourdieu e Passeron criticaram a ideia de uma condiçấo estudantil homogênea entre os universitários franceses. Enfatizaram que a origem social dos estudantes é o mais importante fator de diferenciação, destacando o peso decisivo que os fatores culturais têm na gênese das desigualdades escolares. Fatores estes ligados ao ambiente familiar que propiciaria o acesso às bibliotecas, frequência aos museus, aos teatros, aos concertos, dentre outras atividades que distinguiriam os "estudantes herdeiros" perante outros estudantes, os quais depositariam unicamente na escola a oportunidade de acesso à cultura. Na investigação realizada, embora os estudantes sejam de camadas socialmente mais destituídas, a heterogeneidade dos percursos também aparece como aspecto basilar. Logo, é bem mais preciso falar em bolsistas do ProUni. É possível visualizar uma diferenciação entre bolsistas alocados nas universidades mais prestigiadas, com formato mais tradicional em termos de duração (quatro a cinco anos), sendo alunos mais jovens e situados na faixa etária considerada ideal para a entrada no ensino superior (18 a 24 anos), moradores dos bairros mais próximos do centro paulistano, dentre outras características que os tornam socialmente melhor posicionados - bacharelandos. Por outro lado, há os bolsistas alocados nas instituiçóes menos prestigiadas, com formato menor de duração do curso universitário - alguns, com duração bem enxuta em termos de carga horária -, cuja concorrência pelas vagas é baixa, com maiores desvantagens sociais: geralmente em idade mais avançada, moradores de bairros mais afastados do centro paulistano - alguns periféricos e moradores de outros municípios e da periferia da Grande São Paulo. Esse subgrupo de bolsistas, que constitui a maioria dos investigados - e, sob hipótese plausível, a maioria dos bolsistas do Programa Universidade para Todos ${ }^{4}$ - está representado, sobretudo, pelos licenciandos e tecnólogos.

Referente às condições familiares e culturais temos, para os subgrupos de licenciandos e tecnólogos, a predominância de pais migrantes, sobretudo de origem rural e com baixa escolaridade. Em contraposição, no grupo dos bacharelandos encontramos pais nascidos na capital de São Paulo, que possuem ensino superior ou com ensino médio completo, ou seja, pais com maior escolaridade dentre os pesquisados e, destaca-se, ausência de pais analfabetos. Uma informação central, pois, como apontam estudos no Brasil e no exterior, a alta escolaridade dos pais - e isso é um dos achados que Bourdieu e Passeron chamaram atenção de forma pioneira -, sobretudo a materna, é forte condicionante para o sucesso escolar dos filhos. (REAY, 1998; 2000; SAMPAIO, LIMONGI; TORRES, 2000, p. 22) Outros indicadores das condiçóes culturais também demonstram que os bolsistas bacharelandos estão mais bem equipados. Quando consideramos a lei- 
tura, vemos que os bacharelandos liam e leem mais assiduamente e que as leituras realizadas extrapolam os livros de cunho estritamente escolar. Em contrapartida, os tecnólogos e licenciandos liam menos, sendo que alguns passaram a fazê-lo na universidade e as leituras estão mais restritas às exigências escolares. No que tange à realização de cursos extracurriculares, a predominância localiza-se nos cursos de tipo profissionalizante para todos os bolsistas pesquisados. Porém, chama a atenção que aparecem, somente entre os bacharelandos, cursos ligados à fruição cultural (pintura em tela, balé, saxofone, teoria musical, teatro, flauta).

Bourdieu e Passeron em Os Herdeiros, mediante análise sociológica, na época uma inovação no modo de análise dos dados em relação aos estudos até então existentes, marcados pelo caráter descritivo e pouco conceitualizado (MASSON, 2001), chamam a atenção para os limites do processo de democratizaçáo do ensino superior. Vejamos a "escolha" do curso universitário. O termo deve vir entre aspas para não dar a impressão de que se parte de alternativas disponíveis e abertas a todos, turvando, assim, os diversos atributos sociais que constrangem grande parte de indivíduos. Em outros termos, a "escolha” do curso é limitada pela condição objetiva que marca quem escolhe e o que lhe é dado, concretamente, escolher. (BOURDIEU, 1998, p. 47; 51) Ao questionarmos os motivos para "escolha" do curso que fazem, entre os licenciandos e tecnólogos, despontam a proximidade da residência e, sobretudo, a oportunidade em si de fazer um curso superior como fatores dominantes. A fala de uma estudante de tecnologia em recursos humanos sintetiza muitos relatos dos licenciandos e tecnólogos "não foi minha primeira opção, foi a única”. Em contraste, para os bacharelandos, sobressaem aspectos ligados à distinção e prestígio da carreira e/ou universidade, posto que fizeram pesquisas sobre os cursos antes de se inscreverem para disputar as vagas. Nos seus relatos sobre a universidade e o curso que fazem, predominam qualificadores socialmente positivos como "bom curso", "a boa qualidade", "a boa universidade". Ora, estamos falando aqui de reconhecimento social do curso e da universidade. Ele é o que embasa o valor do diploma do ensino superior, um valor, antes de tudo, envolto em uma dimensão simbólica. Dimensão que aparece como peça importante, pois os elementos que a compóem podem tanto aumentar quanto diminuir o retorno econômico do "instrumento" que é o diploma. A relevância desse simbolismo social constitui outra das liçóes importantes a serem extraídas de Os Herdeiros, depois mais elaborada por Pierre Bourdieu em várias de suas obras quando discute a noção de capital simbólico

[...] conjunto de significaçóes alcançadas pelo comportamento ou pela pessoa, suscetíveis de serem socialmente reconhecidas como tendo valor e compóe-se de dois aspectos [...] o capital escolar, conjunto de efeitos sociais suscetíveis de serem produzidos pela certificação escolar e o capital cultural, conjunto dos efeitos sociais suscetíveis de ser produzidos por outros aspectos da competência simbólica. (apud PASSERON, 1982, p. 573-4) 
Assim, o subgrupo dos bolsistas considerado mais seleto são portadores tanto do reconhecimento na dimensão escolar já que pertencentes a cursos e universidades tidas como mais prestigiadas e, a um só tempo, possuidores de atributos que os colocam com vantagens na dimensão "cultural" do capital simbólico. Bourdieu e Passeron foram pioneiros em chamar a atenção para a existência de um "mercado simbólico", contrapondo-o à ideologia liberal pautada em preceitos mecanicistas de uma teoria do capital humano (a crítica a termos como "meritocracia", "dom", dentre outros, entra nessa linha). Preceitos que ainda embasam a ilusão de ver na educação algo que por si só, "naturalmente", traria embutido um valor igualitário. Com pesquisas empíricas e elaboraçóes teóricas, revelaram como atuam os mecanismos sociais de uma "herança cultural", responsável pela estruturação dos privilégios culturais entre os grupos e indivíduos:

A “incorporação" do capital cultural e escolar à pessoa [...] faz-se precisamente sobre um mercado simbólico, o valor do capital escolar e cultural. Tal "capital" revela, portanto, uma propriedade bem paradoxal: ele só toma todo seu valor de troca à medida que ele consegue se fazer reconhecer socialmente como propriedade intrínseca da pessoa privada e, correlativamente, a se fazer esquecer como produto ou privilégio social. (PASSERON, 1982 , p. 575-576)

Pergunta: Você ficou quanto tempo na UNIP? Z: Um ano, 2007. Eu percebi que se você tentasse concorrer no mercado de trabalho com a Unip você não tinha boas oportunidades. Estágio de quinhentos reais é muito. P: Quais são as faculdades que eles geralmente querem? Z: PUC, USP e Mackenzie. Não é? Então tchau. P: Você percebeu isso quando? Z: Logo que eu comecei a procurar estágio. Mas nas pesquisas por internet, os estágios melhores exigiam faculdade de primeira linha. Se não tivesse, você nem era qualificado, nem adiantaria mandar o seu currículo. Então, eu percebi que tinha mais dificuldade para entrar no mercado de trabalho. Porque aí eu pensei "eu quero uma faculdade boa pelo menos" [...] Eu vejo assim muitas oportunidades no curso, ainda mais direito na PUC. Você fala que faz direito na PUC o olho da outra pessoa que está te ouvindo brilha, sabe, e se você falar que faz direito na UNIP, torce a cara, é sério [...] E, assim, o curso é um curso bom, então a chance de você estar no quarto, quinto ano em um estágio que pode te registrar é muito alta. Ou a chance de conseguir um trainee [cargo ocupado por jovens recém-formados ou em vias de formaçấo, geralmente após processos seletivos concorridos] em qualquer empresa grande, também. (Z, estudante, direito, PUC-SP)

A desigual eficácia do valor simbólico do diploma fica evidente ao percorrermos os indicativos empíricos coletados sobre a universidade e os cursos 
que os bolsistas do ProUni frequentam. Para os bacharelandos, o diploma reveste-se de um valor simbólico positivo enquanto título escolar em contraposição aos pesquisados dos cursos tecnológicos de curta duração e nas licenciaturas com baixa carga horária, estes mais calcados no "puro" valor instrumental da posse do diploma, marcados por uma menor distinção simbólica. É preciso reter que a posse do diploma de ensino superior ainda faz diferença em termos de retorno financeiro, conforme aponta a pesquisa de Carvalho (2011, p. 85-86). Entretanto, por meio de análise qualitativa de vários pontos das trajetórias pesquisadas, há uma série de aspectos inter-relacionados que marcam os cursos desclassificados: faculdades desprestigiadas, formato curto do curso, baixa avaliação no Exame Nacional de Desempenho de Estudantes (Enade), baixo retorno financeiro, relatos sobre instalaçóes improvisadas, qualidade precária dos professores, dentre outros. É sustentável dizer que o Programa Universidade para Todos, para o segmento predominante de estudantes pesquisados, acrescenta um diploma de ensino superior com peso menos efetivo. E é justamente nesse ponto que se justifica entender, plenamente, a estrutura do ensino superior privado lucrativo brasileiro atual, terreno no qual está sendo formada a maioria dos bolsistas. O fato essencial é que, atualmente, há uma nova configuração (ALMEIDA, 2014) ocorrendo em tal segmento, manifesta no domínio dos fundos de investimentos com ações na Bolsa de Valores. A implicação é que a gestão de fundos de investimentos, pautada na ação negociada na Bolsa, introduz a lógica do curto prazo (o resultado do desempenho da ação, trimestral) em detrimento da lógica do médio e do longo prazo (requerida pela educação, mesmo que esta seja tratada como um "produto" qualquer). Eis o paradoxo: exige-se reduzir custos para maximizar o retorno dos investimentos, porém, reduzi-los - leia-se, principalmente, demitir professores mais bem formados - significa entregar, cada vez mais, qualidade educacional precária aos estudantes.

Em consequência, a discussão sobre a qualidade dos cursos e das universidades que os bolsistas frequentam, sem dúvida, constituem elementos fundamentais. Nesse particular, os esclarecimentos de Bourdieu e Passeron em Os Herdeiros continuam pertinentes para aqueles que têm como foco privilegiado de estudo o acesso e a permanência no ensino superior: a relegação às denominadas "carreiras de refúgio", a "auto-exclusão no interior do ensino superior", retomada depois em Bourdieu e Champagne (1992). As maiores proporçóes dos licenciandos e dos tecnólogos nem tentaram os vestibulares das universidades públicas. Entre os bacharelandos, a proporção maior prestou o vestibular da universidade pública uma vez e não passou mesmo em cursos de baixa concorrência. Estão relegados aos cursos mais desprestigiados no interior do sistema privado lucrativo. Ao fim e ao cabo, para um segmento social bem específico e menor, geralmente extraído da baixa classe média, o Programa Universidade para Todos acaba funcionando como um acelerador do processo de ingresso no ensino superior nas carreiras mais concorridas: 
Pergunta: Se você não tivesse o ProUni, você ainda insistiria para tentar... L: Se eu não tivesse o ProUni eu teria ingressado no curso de tecnologia. Eu cheguei a me matricular no curso de tecnologia do Cefet (Centro de Educação Tecnológica, instituição técnica federal) [...] com o ProUni foi melhor, porque já é engenheiro e não tecnólogo, então facilitou. (L, Engenharia Civil, Mackenzie).

Para a grande maioria dos bolsistas, de mais baixa renda, marcados por restriçóes financeiras e competitivas frente a outras fraçóes de classe social na disputa pelas vagas das universidades públicas, o programa constituiu a única oportunidade para fazer um ensino superior. Tal fato repóe discussóes e desafios importantes em torno da questão do ingresso no ensino superior público brasileiro, ainda timidamente permeável ao atendimento de demandas legítimas desses trabalhadores-estudantes e, no mesmo movimento, aponta para a inclusão social e importância que o ProUni possui e a qual não se pode, sem mais, descartar.

Mais uma contribuição propiciada por Bourdieu e Passeron, antevista nessa obra fundamental que é Os Herdeiros, tem relação com um conceito polêmico na sociologia da educação por eles desenvolvida - o clássico debate do "reprodutivismo". Trata-se da noção de reprodução social, elaborada na crítica que ambos fizeram à tese da igualdade das oportunidades escolares entre as diferentes classes sociais. (PASSERON, 1986) No registro conceitual desses autores, reprodução não significa simplesmente uma situação social que se conserva imutável, tal qual era antes. Ela não se configura como algo estático, parado no tempo e, sim, dinâmico, já que referida a uma relação social desigual transformada:

Designa e interroga a continuidade no tempo das relações de força e de sentido entre classes que fundam o essencial das diferenças e dos antagonismos coletivos observáveis em uma sociedade, a variação ou a repetição das trajetórias que conduz de uma geração à outra, os indivíduos às posiçóes diferentes ou idênticas àquelas de seus pais [...] é um fato: desde que a demanda escolar de novas categorias sociais encontrou os meios de se exprimir e de transformar o recrutamento da escola, é todo o sistema das relaçóes entre certificação escolar e estratificação social que, em se transformando, tendeu a minimizar os efeitos sociais da primeira transformação [...] chamar 'reprodução' a atitude (constatada, descrita e medida) de uma estrutura desigual que incorpora o processo de igualdade em uma forma transformada de desigualdades. (PASSERON, 1982, p. 565-567) [grifos do autor]

Ora, o aumento das taxas de escolarização em todas as classes sociais, envolto em um novo arranjo de disparidades, acaba por despotencializar o impulso 
democratizador da educação. Essa a lição de ambos. Além desse caráter dinâmico, faça-se justiça, tal noção também não se reveste de um caráter fatalista. É preciso destacar: a escola contribui/pode contribuir para a reprodução social, é um dos espaços sociais na qual é possível visualizar a segmentação social entre as fraçóes de classe. Entretanto, como disposto na conclusão de Os Herdeiros, eles enfatizam a possibilidade de atenuar as desigualdades tendo em vista um ensino mais democrático - toda a discussão do que designam como uma "pedagogia racional". Oriundos de famílias da baixa classe média que estavam fora do circuito central de prestígio e poder francês sabiam, como poucos, das dificuldades impostas pelo "curso magistral" aos estudantes universitários "não herdeiros". O tema ainda é bem atual, senão vejamos:

[...] a universidade de massa tem largamente mantido um modelo pedagógico principalmente fundado sobre o curso magistral e na autonomia do trabalho pessoal [...] não permite preencher as lacunas dos estudantes menos dotados escolarmente e pode colocá-los gravemente em dificuldade. (BEAUD, 2008, p. 156)

A instituição escolar pode legitimar as diferenças culturais entre os grupos sociais tal como demonstram as estatísticas dispostas em Os Herdeiros, mas, por outro lado, pode também cumprir um papel na diminuição das desigualdades no acesso à cultura

[...] a escola poderia compensar - pelo menos parcialmente - a desvantagem inicial daqueles que, em seu meio familiar, não encontram a incitação à prática cultural. Pois, ao não tentar ao menos fazê-lo, a instituição escolar neste sentido adquire caráter reprodutor [...] ao omitir de fornecer a todos, o que alguns recebem da família, o sistema escolar perpetua e sanciona as desigualdades iniciais. (BOURDIEU; DARBEL, 2003, p. 103)

\section{Considerações finais}

Guardada a lembrança de que os resultados aqui discutidos estão ligados ao universo empírico da cidade de São Paulo e os limites de acesso às informaçóes básicas do ProUni, enfrentados pelos pesquisadores junto ao MEC - para ficar no essencial, qual a quantidade de bolsas distribuídas por curso, em cada instituição? - algumas consideraçóes podem se mostrar frutíferas para outros estudos e pesquisas sobre essa temática. Faz-se necessário reconhecer e destacar que o ProUni apresenta-se como uma alternativa para o estudante de baixa renda, marcado por restriçóes financeiras e por barreiras competitivas nos concorridos vestibulares das universidades públicas. Todavia, verifica-se uma segmentação entre os bolsistas 
pesquisados. De um lado, há um grupo pequenino, de extração social mais próxima a uma baixa classe média, para o qual o ProUni funciona como um "acelerador" do processo de entrada na educaçáo superior, principalmente nas carreiras mais prestigiadas e concorridas, conquistando, dessa forma, diplomas de reconhecido valor simbólico. Por outro lado, perfazendo a maioria dos bolsistas pesquisados tem-se uma extração social de mais baixa renda, o programa consistindo na "oportunidade única” para fazer o ensino superior e, por sua vez, obtendo diplomas de baixo reconhecimento simbólico em instituições de baixa qualidade educacional.

Dessa forma, os dados empíricos coletados e analisados referentes às trajetórias familiares, ocupacionais, de acesso e de permanência na universidade, denotam uma heterogeneidade interna, sugerindo diferenças importantes entre os bolsistas, com acentuada positividade para os bacharelandos no que se refere à formação escolar, origem social e econômica, bem como condiçóes culturais. Em decorrência dessas vantagens comparativas, os bacharelandos acessam cursos e universidades mais prestigiadas, principalmente os bolsistas das universidades confessionais (Mackenzie e PUC-SP), em comparação com os subgrupos formados pelos tecnólogos e licenciandos, estes últimos em posiçôes sociais mais desvantajosas. Ao relacionarem a instituição escolar e a distribuição do capital cultural entre os indivíduos, procurando verificar as interaçóes entre as estratégias familiares das diversas classes sociais e a lógica particular da escola, Pierre Bourdieu e Jean Claude Passeron, em Os Herdeiros, forneceram elementos essenciais para uma compreensão mais densa sobre o sentido e a dinâmica do acesso ao ensino superior das camadas, social e culturalmente, menos favorecidas. Foram pioneiros na análise sociológica crítica do tão disseminado potencial "democratizador do ensino superior", procurando apontar seus processos e mecanismos contraditórios. Com essa obra, legaram-nos ferramentas heurísticas relevantes para todos os que têm as desigualdades educacionais e culturais como foco de estudo. Para o caso em tela, permitiram-nos apreender os mecanismos desiguais que acompanham o processo de abertura do ensino superior às camadas brasileiras de mais baixa renda na última década.

O ProUni possui o diferencial de ter possibilitado que indivíduos mais velhos, casados, com filhos, provedores de família e moradores de bairros periféricos pudessem acessar o ensino superior. No mesmo movimento de análise, é preciso também ter em conta, sob questão, em quais carreiras e sob quais condiçóes. Em decorrência, não se pode desconsiderar ou condenar o programa pelo fato dele se constituir uma opçáo para o estudante brasileiro das camadas populares. No entanto, é preciso também não o glorificar sem mais - para não o essencializar -, fechando os olhos para as desigualdades que permeiam todo o processo de ampliação do acesso ao ensino superior que o Programa Universidade para Todos vem propiciando em uma sociedade ainda permeada por múltiplas desigualdades como a brasileira. Logo, penso que é contestável, de partida, falar 
em mobilidade social - tal qual discursos correntes o fazem - a partir do acesso que o Programa propiciou para milhares de jovens de baixa renda oriundos da escola pública. Ingressar no ensino superior é uma dimensão - importante, sem dúvida -, todavia outras dimensóes devem ser levadas em consideração para melhor aquilatar o impulso em termos de ascensão social que se pode obter pela passagem pelo ensino superior propiciada por essa política pública. Não se trata, portanto, de diminuir a importância desse impulso, mas, sim, de considerá-lo criticamente, apontando os avanços e limites que o constituem. Sob essa perspectiva, o programa é constrangido pelos mesmos obstáculos enfrentados por outras políticas de acesso: a imensa desigualdade social existente no país, a estrutura também muito desigual do mercado de trabalho, as diferenças culturais, o custo de vida das grandes metrópoles, as condiçóes familiares, dentre outros aspectos que complexificam esse tema.

Com efeito, para retomar a reflexão antes delineada sobre os sentidos do termo democratização do ensino, à luz da pesquisa empírica realizada com os 50 bolsistas da cidade de São Paulo, com o ProUni o processo de democratização do ensino superior não consegue realizar-se por completo ao não avançar na sua face qualitativa, contemplando dimensóes ligadas às particularidades do conhecimento que se obtém. Este ponto crucial deve ser considerado quando se discute desigualdades educacionais. Para quais bolsistas se aplica, efetivamente, o termo democratização do ensino superior em seu sentido pleno, tanto no seu aspecto quantitativo quanto qualitativo? Para todos? Para a maior parte deles? No essencial, tais questionamentos repõem as indagaçóes e indicativos heurísticos desenvolvidos nas pesquisas empíricas e elaboraçóes conceituais de Pierre Bourdieu e Jean Claude Passeron visando dar ao tema da educação um tratamento sociológico mais rigoroso. Nos seus termos, caberia perguntar: democratização ou reprodução, uma relação desigual "transformada"? Nos seus cinquenta anos, Os Herdeiros, uma das expressóes do esforço teórico empreendido por ambos, ainda mantém sua vivacidade analítica.

\section{Notas}

1. Dentre os diversos autores que pesquisaram a emergência desse setor mercantil, cabe destacar o trabalho de Carlos Benedito Martins que o denominou como "novo ensino superior privado" para diferenciá-lo do ensino superior privado confessional, até então dominante. Para maiores detalhes, consultar Martins (1987; 1989; 2009).

2. O sistema permite a seleção dos ingressantes a partir da nota do Enem, possibilitando ao candidato concorrer às vagas disponíveis nos estabelecimentos federais que participarem do sistema, ensejando assim maior possibilidade de disputa pelas vagas existentes nos estados brasileiros. Atualmente, todas as 59 universidades federais de alguma forma utilizam a nota do Enem - totalmente, a grande maioria delas; em parte, poucas instituiçóes - em seus processos seletivos.

3. Para uma reconstruçáo histórica do ensino superior privado lucrativo brasileiro, das faculdades isoladas até o predomínio atual dos fundos de investimento, consultar Almeida (2014). 
4. É de amplo conhecimento entre os pesquisadores que o MEC nẫo disponibiliza informações fundamentais para um delineamento do perfil dos bolsistas do ProUni, notadamente, em quais carreiras e em quais universidades estão, dentre outros pontos correlatos relevantes.

\section{Referências}

ALMEIDA, W. M. USP para todos? estudantes com desvantagens socioeconômicas e educacionais e fruição da universidade pública. SP: Musa/FAPESP, 2009.

. ProUni e o ensino superior privado lucrativo em São Paulo: uma análise sociológica. SP: Musa/FAPESP, 2014.

BEAUD, S. "Le fac, c'est moins pire que je croyais!": sur certaines contradictions de l'université d'aujord'hui. Revue Du MAUSS, v. 2, n. 28, p. 323-333, 2006.

. Enseignement Supérieur: la "démocratisation scolaire" en panne. Formation emploi, v. 1, n. 101, p. 149-165, 2008.

BEAUD, S.; PIALOUX, M. Les "bacs pro" à l'université: récit d'une impasse. Revue française de pédagogie, n. 136, p. 87-95, 2001.

BOURDIEU, P. Escritos da Educação. Petrópolis: Vozes, 1998. [Organizado por Maria Alice Nogueira e Afrânio Catani].

BOURDIEU, P.; CHAMPAGNE, P. Les exclus de l'interieur. Actes de la recherche en sciences sociales, Paris, n. 91/92, p. 71-75, 1992.

BOURDIEU, P.; DARBEL, A. Obras culturais e disposição culta. In: BOURDIEU, P.; DARBEL, A $O$ amor pela arte: os museus da arte na Europa e seu público. SP: Editora Zouk, 2003. p. 69-111.

BOURDIEU, P.; PASSERON, J. -C. Les héritiers, lés étudiants et la culture. Paris: Ed. Minuit, 1964.

. Os herdeiros: os estudantes e a cultura. Florianópolis: Ed. da UFSC, 2014.

$\overline{\text { Minuit, } 1970 .}$

CARVALHO, M. M. A Educação Superior no Brasil: o retorno privado e as restrições ao ingresso. Sinais Sociais, Rio de Janeiro, v. 5, n. 15, p. 82-111, jan./abr. 2011.

COMIN, A. A.; BARBOSA, R. J. Trabalhar para estudar: sobre a pertinência da noção de transição escola-trabalho no Brasil. Novos Estudos CEBRAP, n. 91, p. 75-95, 2011.

CUNHA, L. A. A Expansão do Ensino Superior: Causas e Conseqüências. Debate e Crítica, n.5, p. 27-58, 1975.

. O Ensino Superior no Octênio FHC. Educação e Sociedade, Campinas, v. 24, n. 82, p. 37-61, abril 2003. 
DAUSTER, T. "Uma revolução silenciosa": notas sobre o ingresso de setores de baixa renda na universidade. In: ENCONTRO ANUAL DA ANPOCS, 27., 2003, Caxambu. Anais... Caxambu, 2003, p. 1-22.

ERLICH, V. Les nouveaux étudiants: une groupe social en mutation. Paris: Armand Colin, 1998.

FERNANDES, F. A democratização do ensino. In: FERNANDES, F. Educação e sociedade no Brasil. SP: Edusp/Dominus, 1966, p. 123-134.

FILHO, R. M.; OLIVEIRA, R. P.; CAMARGO, R. B. Tendências da matrícula no ensino fundamental regular no Brasil. In: OLIVEIRA, C. et al. Municipalizaçâo do Ensino no Brasil: algumas leituras. BH: Autêntica, 1999, p. 37-60.

GARCIA, S.; POUPEAU, F. La mesure de la "démocratisation" scolaire: notes sur les usages sociologiques des indicateurs statistiques. Actes de La Recherche en Sciences Sociales, Paris, n. 149, p. 74-87, 2003.

HIRANO, S. et al. A universidade e a identidade da condição estudantil: um estudo sobre a situação socioeconômica, níveis de saúde e modo de vida dos estudantes da USP. Temas IMESC, SP, v. 4, n.1, p. 83-108, 1987.

KERSTENETZKY, C.; UCHOA, C. Moradia inadequada, escolaridade insuficiente, crédito limitado: em busca da nova classe média. Textos para Discussão, n. 76, CEDE/UFF. Niterói, RJ, 13p. 2013.

LANGOUËT, G. French schools are changing: but post-school transition is becoming more and more difficult. Australian Journal of Education, v. 46, n. 2, p. 121-137, 2002.

MARTINS, C. B. Privatização: a Política do Estado Autoritário para o Ensino Superior. Cadernos Cedes, Campinas, n.5, p. 43-61, 1987.

. O novo ensino superior privado no Brasil (1964-1980). In: MARTINS, C. B. (Org.). Ensino Superior Brasileiro: transformaçôes e perspectivas. SP: Brasiliense, 1989, p. 11-48.

. A Reforma Universitária de 1968 e a abertura para o ensino superior privado no Brasil. Educação e Sociedade, Campinas, v. 30, n. 106, p. 15-35, jan./abr. 2009.

MASSON, P. La fabrication des Héritiers. $R$. franç. sociol., Paris, v. 42, n.3, p. 477-507, 2001.

MERLE, P. Le concept de démocratisation de l'institution scolaire: une typologie et sa mise à l'épreuve. Population, v. 55, n. 1, p. 15-50, 2000.

MOEHLECKE, S. Fronteiras da Igualdade no Ensino Superior: Excelência \& Justiça Racial. 2004. 231f. Tese (Doutorado em Educação) - Faculdade de Educação. Universidade de São Paulo, São Paulo. 2004.

NERI, M. C. (Org.). A nova classe média: o lado brilhante da base da pirâmide. SP: Saraiva, 2011.

PASSERON, J.-C. L'inflation des diplomes: remarques sur l'usage de quelques concepts analogiques en sociologie. $R$. franç. sociol., Paris, v. 33, p. 551-584, 1982. 
PASSERON, J. C. Hegel ou le passager clandestin, la reproduction sociale e l'histoire. Esprit, n. 115, juin. 1986.

POCHMANN, M. Nova classe média? o trabalho na base da pirâmide social brasileira. SP: Boitempo, 2012.

. O Mito da grande classe média: capitalismo e estrutura social. SP: Boitempo, 2014.

REAY, D. Class Work: Mother's Involvement in Their Children's Schooling. London: University College Press, 1998.

. A useful extension of Bourdieu's conceptual framework? Emotional capital as a way of understanding mother's involvement in their children's education. Sociological Rewiew, n. 48, p. 568-585, 2000.

RIBEIRO, S. C.; KLEIN, R. A divisão interna da universidade: posição social das carreiras. Educação e Seleção, v.5, p. 29-43, 1982.

SAMPAIO, H. (Coord.); LIMONGI, F.; TORRES, H. Equidade e Heterogeneidade no Ensino Superior Brasileiro. Brasília: Inep, 2000.

SOUZA, A.; LAMOUNIER, B. A classe média brasileira: ambiçôes, valores e projetos de sociedade. RJ: Elsevier; Brasília: CNI, 2010.

SOUZA, J. Os batalhadores brasileiros: nova classe média ou nova classe trabalhadora? Belo Horizonte: Ed. UFMG, 2010.

SOUZA, P. R. Avaliar, qualificar, expandir. Ensino Superior, p. 10-20, janeiro 1999. 2005 . . A Revolução Gerenciada: educação no Brasil (1995-2002). SP: Prentice Hall,

SPOSITO, M. P.; ANDRADE, C. L. O aluno do curso superior noturno: um estudo de caso. Cadernos de Pesquisa, v. 57, p. 3-19, 1986.

ROMANElli, O. O. História da Educação no Brasil (1930-1973). Petrópolis: Vozes, 2001.

TARTUCE, Gisela Lobo B. P. Tensões e intenções na transição escola-trabalho: um estudo das vivências e percepçóes de jovens sobre os processos de qualificação profissional e (re) inserção no mercado de trabalho na cidade de São Paulo. 2007. 441f. Tese (Doutorado) - Departamento de Sociologia, Faculdade de Filosofia, Letras e Ciências Humanas. Universidade de São Paulo, São Paulo. 2007.

Recebido em 21 de agosto de 2014.

Aprovado em 09 de março de 2015. 